•研究报告・

\title{
罗霄山脉翼手目物种多样性及适生区预测
}

\author{
胡宜峰 ${ }^{1}$ 王晓云 ${ }^{1}$ 邓学建 ${ }^{2}$ 吴 华 ${ }^{3}$ 黄正澜懿 ${ }^{1}$ 岳 阳 ${ }^{1}$ 黎 $^{\text {舫 }^{1}}$ 张秋萍 $^{1}$ \\ 郭伟健 ${ }^{1}$ 李 锋 ${ }^{1}$ 陈柏承 ${ }^{1}$ 徐忠鲜 ${ }^{1}$ 周 全 ${ }^{1}$ 余文华 ${ }^{*}$ 吴 毅 ${ }^{*}$ \\ 1 (广州大学生命科学学院, 广州 510006) \\ 2 (湖南师范大学生命科学学院, 长沙 410081) \\ 3 (华中师范大学生命科学学院, 武汉 430079)
}

摘要：罗霄山脉位于中国大陆东南部，是一条南北走向的大型山脉，面积约6.76万 $\mathrm{km}^{2}$ 。该山脉位于欧亚大陆东部 季风区, 生物多样性丰富, 是亚洲东部第三纪冰期动物重要的避难所。为了解罗霄山脉翼手目物种多样性状况, 本 研究组于2013-2018年, 使用雾网、手网和坚琴网等工具开展了针对性调查与标本采集, 同时运用形态分类学和分 子系统发生学方法鉴定物种。根据调查结果并结合文献记载: 罗霄山脉地区现有翼手目物种4科14属40种, 其中罗 霄山脉翼手目新记录种 25 种, 省级翼手目分布新记录种 9 种。同时, 本研究基于5年的调查采集位点, 使用生物多样 性与气候变化虚拟实验室(the Biodiversity \& Climate Change Virtual Laboratory)在线生境预测平台, 对罗霄山脉翼 手目物种当前的适生区，以及3种不同量温室气体排放情景下(representative concentration pathway, RCP 2.6 / 6.0 / 8.5) 2050年的适生区进行预测, 其中随机森林算法(random forest)的模型解释力较优, 其预测结果显示: 影响该区 域翼手目分布的主要环境因子为降水季节性和年平均温度; 山脉中部及南部为翼手目的高适生区, 面积约为罗霄 山脉的30\%; 与当前适生区相比, RCP 2.6情景下2050年该类群适生区有所扩增, RCP 6.0和RCP 8.5情景下均会导致 翼手目适生区急剧缩减, 且分布区将迁移至高海拔区域以响应气候变化。而本项目的开展不仅初步掌握了罗霄山 脉翼手目物种多样性本底状况, 也为开展后续的翼手目研究和保护管理提供了参考。

关键词: 翼手目(蝙蝠); 罗霄山脉; 物种多样性; 生境预测

\section{Species diversity and suitable habitat prediction of Chiroptera in the Luoxiao Mountains}

Yifeng $\mathrm{Hu}^{1}$, Xiaoyun Wang ${ }^{1}$, Xuejian Deng ${ }^{2}$, Hua $\mathrm{Wu}^{3}$, Zhenglanyi Huang ${ }^{1}$, Yang Yue ${ }^{1}, \mathrm{Fang} \mathrm{Li}^{1}$, Qiuping Zhang ${ }^{1}$, Weijian Guo ${ }^{1}$, Feng $\mathrm{Li}^{1}$, Bocheng Chen ${ }^{1}$, Zhongxian $\mathrm{Xu}^{1}$, Quan Zhou ${ }^{1}$, Wenhua Yu ${ }^{{ }^{*}}$, $\mathrm{Yi} \mathrm{Wu}{ }^{1 *}$

1 School of Life Sciences, Guangzhou University, Guangzhou 510006

2 School of Life Sciences, Hunan Normal University, Changsha 410081

3 School of Life Sciences, Central China Normal University, Wuhan 430079

\begin{abstract}
The Luoxiao Mountains are a main chain of north-south mountains in southeast China, covering approximately $67,600 \mathrm{~km}^{2}$. It is considered a biodiversity hot spot that served as glacial refuge during the Tertiary period for eastern Eurasia. Starting in 2013, we investigated chiropteran diversity in the Luoxiao Mountains by conducting five-year surveys using mist nets, hand nets and harp traps. We identified 40 chiropteran species belonging to 4 families, 14 genera through morphological examination, phylogenetic inference, comparing to species identification from the literatures. Of the species we identified, 25 are primarily found in the region, and 9 belong to new provincial records. Current and potential future distribution area for bats was predicted based on all occurrence coordinates using the online platform "the Biodiversity \& Climate Change Virtual Laboratory”. The random forest algorithm performed better than all other methods, and further indicates that precipitation seasonality and annual mean temperature contribute
\end{abstract}


the most in models. Additionally, we found that the central and southern region (about 30\% of the Luoxiao Mountains area) are hot spots for bats. The future distribution prediction for 2050 illustrates a trend of range expansion under the lowest greenhouse gas emissions conditions (RCP 2.6). Nevertheless, suitable habitats for bats will dramatically contract and transfer to higher regions under RCP 6.0 and RCP 8.5. We hope this study benefits future research, conservation and management for chiropteran in the Luoxiao Mountains.

Key words: Chiroptera (bats); Luoxiao Mountains; species diversity; habitat prediction

罗霄山脉位于中国大陆东南部, 纵跨湖北、湖 南和江西三省 $\left(112^{\circ} 20^{\prime}-115^{\circ} 50^{\prime} \mathrm{E}, 25^{\circ} 20^{\prime}-30^{\circ} 00^{\prime} \mathrm{N}\right)$, 是一条历史悠久、成因复杂、呈东北-西南方向的 大型山脉，面积约6.75万 $\mathrm{km}^{2}$, 主要包括诸广山脉、 万洋山脉(井风山、南风面、七溪岭)、武功山脉(羊 狮幕)、九岭山脉和幕阜山脉等 5 个中型山脉。该区 域为中国大陆东部第三阶梯最重要的气候和生态 交错区, 具有较高的生物多样性, 同时该区域也是 亚洲东部最重要的脊椎动物聚集地与东西替代、南 北迁徙的生物地理通道(廖文波等, 2014; 魏识广等, 2015; 宫辉力等, 2016), 具有重要的研究价值和保 护意义。目前对于罗霄山脉的本底调查主要集中在 昆虫与植物类群(吕泽㑆, $2015^{\circledR}$; 谢喃喃, $2015^{(2)}$; 陈宜平, $2016^{\circledR}$; 赵万义, 2017), 而哺乳动物调查记 录尚较零散, 缺乏系统性研究。

翼手目是哺乳纲中仅次于啮齿目的第二大目 (Simmons, 2005), 是生态系统中的关键成员，具有 重要生态作用(Williamsguillén et al, 2008; Kunz et al, 2011; Boyles et al, 2011; Wanger et al, 2014; Maine \& Boyles, 2015)。然而, 由于翼手目种类具有飞行能力, 且生活环境隐蔽, 故本底资料相对匮乏。除廖文波 等(2014, 2018)分别对万洋山脉的井冈山地区与湖 南桃源洞国家级自然保护区的翼手目资源有所报 道, 迄今未见针对性的专项调查。从2013年到2018 年, 我们对罗霄山脉的 5 个中型山脉及自然保护区 开展了翼手目物种多样性实地调查, 获得该区域翼 手目物种多样性名录与分布状况。此外, 我们也运 用物种分布模型(species distribution modeling, SDM, Hallgren et al, 2015)对罗霄山脉翼手目当下及未来 的适生区分别进行预测, 以期为后续针对性调查提 供引导, 同时也为该类群的研究、保护管理及疾病

(1)吕泽㑆 (2015) 中国罗霄山脉昆虫区系特征及多样性初步调查. 硕士 学位论文, 上海师范大学, 上海.

(2)谢喃喃 (2015) 中国罗霄山脉隐翅虫科区系特征及多样性初步研究. 硕士学位论文, 上海师范大学, 上海.

(3)陈宜平 (2016) 中国罗霄山脉昆虫区系特征及多样性初步研究 (二). 硕士学位论文, 上海师范大学, 上海.
防控提供基础资料。

\section{研究方法}

\section{1 蝙蝠野外调查方法}

2013-2018年，使用网捕法(包括雾网、手网和 坚琴网)完成对罗霄山脉地区33个样点的翼手目调 查(图1)。洞穴型蝙蝠的调查采取架设雾网或直接进 洞捕获方式采集; 树栖型蝙蝠通过在蝙蝠潜在飞行 路线架设坚琴网或雾网采集; 房屋型蝙蝠则通过在 保护区内的保护站及村庄附近林道中架设雾网，同 时结合手网采集。

\section{2 标本鉴定方法及依据}

对采集的蝙蝠标本进行外部形态的测量, 包

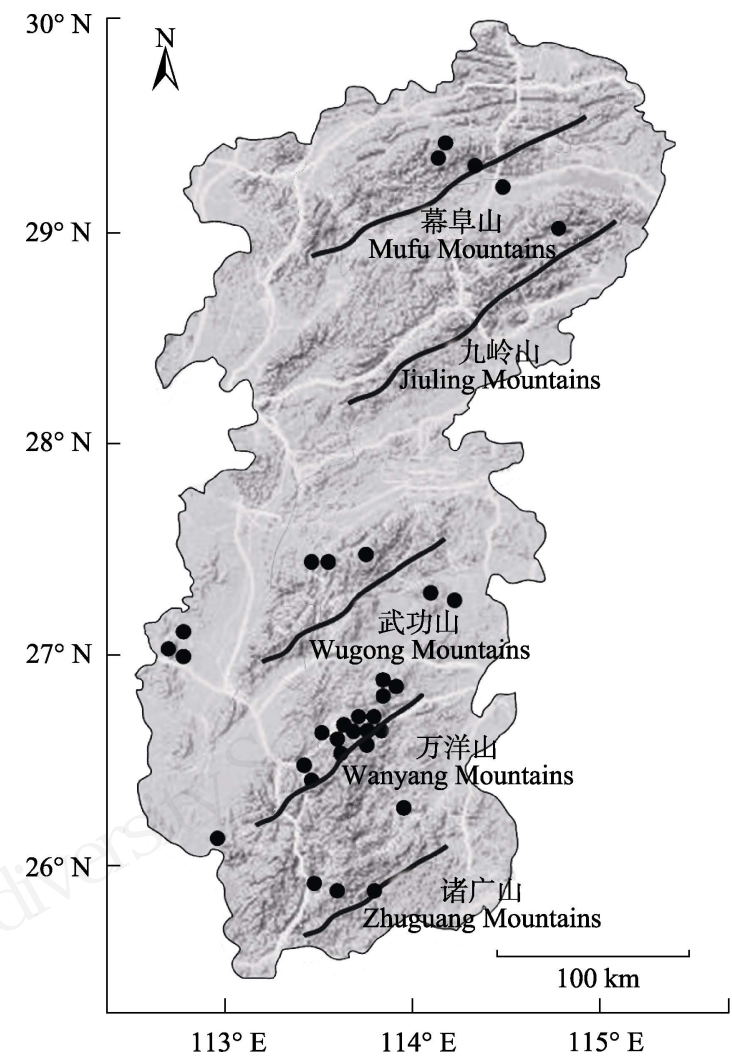

图12013-2018年罗霄山脉翼手目调查样点示意图

Fig. 1 The site of Chiropteran investigation in the Luoxiao Mountains between 2013 and 2018 
括：前臂长(forearm length)、尾长(tail length)、后足 长(hindfoot length)、胫骨长(tibia length)、耳长(ear length) (Bates \& Harrison, 1997; 杨奇森等, 2007)。 依据《中国哺乳动物种和亚种分类名录与分布大 全》(王应祥, 2003)和《中国兽类图鉴》(刘少英和 吴毅, 2019)进行物种的鉴定。对于部分难以通过外 部形态特征鉴定的物种, 运用头骨形态学与分子系 统发育学分析方法辅助鉴定。

鉴于体型较小的鼠耳蝠 (Myotis)、伏翼 (Pipistrellus)、管鼻蝠(Murina) 等类群的外部形态极 为相似, 除检视头骨特征外, 还借助分子系统发育 学方法辅助物种鉴定。剪取肌肉或肝脏组织约 $20 \mathrm{mg}$, 使用DNA提取试剂盒(Tiangen, 天津)提取总DNA。 根据类群在NCBI-nt (GenBank)数据库中的信息丰 度与覆盖度选择合适的分子标记及外群, 对管鼻蝠 (外群: Pipistrellus subflavus)及伏翼(外群: 圆耳管鼻 蝠(Murina cyclotis))使用线粒体COI基因, 对鼠耳蝠 类群(外群：普通伏翼(Pipistrellus pipistrellus))则使 用 $C y t b$ 基因。其扩增引物分别为: COI基因 (F: 5'-ACA GCC TAA TAC CTA CTC GGC CAT-3'; R: 5'-AGG CTC GGG TGT CTA CGT CCA-3'), Cyt $b$ 基 因(F: 5'-AAA TCA CCG TTG TAC TTC AAC-3'; R: 5'-TAG AAT ATC AGC TTT GGG TG-3')。扩增产物 送至上海美吉生物科技公司测序，使用GENEIOUS 5.4 (Drummond et al, 2011)对测序结果进行目测校 对与拼接, 结合GenBank数据库中下载的基因序列 使用Muscle (Edgar, 2004)进行排序, 运用ModelTest (Posada \& Crandall, 1998)确定最优化核苷酸替换模 型，使用RAxML (Stamatakis, 2014)构建COI和Cyt b 基因的最大似然系统发育树 (maximum likelihood tree, ML tree), 自展法自展100次评估节点支持度。

\section{3 翼手目多样性编目及适生分布区预测}

在本研究组5年翼手目资源调查的基础上, 整 合梳理该类群在罗霄山脉已有分布记录(丁铁明和 王作义, 1989; 江廷否等, 2007; 郭新春等, 2010; 徐 忠鲜等，2013; 廖文波等，2014，2018; 张秋萍等, 2014; 陈柏承等, 2015; 李锋等, 2015; 党飞红等, 2016; 任锐君等, 2017; 王英永等, 2017; 冯否等, 2017, 2019; 黄正澜懿等, 2018; 余子寒等, 2018; 岳 阳等, 2019), 对该区域翼手目物种多样性进行编目, 并根据《中国动物地理》(张荣祖, 1999)和《中国脊 椎动物红色名录》(蒋志刚等, 2016)对其进行地理区
系划分和濒危等级评估。

同时，以野外调查的 29 个采集位点信息为依据 (附录1), 在生物多样性与气候变化虚拟实验室平台 (the Biodiversity \& Climate Change Virtual Laboratory, BCCVL; https://app.bccvl.org.au/)对适生 区进行预测，预测模型包括框架模型(profile models) 中 的 Bioclim; 机器学习模型 (machine learning models) 中的人工神经网络模型 (artificial neural network, ANN)、决策树算法(classification tree, CT)、 最大熵模型(MaxEnt)、随机森林算法(random forest, $\mathrm{RF}$ ); 统计回归模型(statistical models)中的多变量自 适应回归样条算法(flexible discriminant analysis, FDA)、广义线性模型(generalized linear model, GLM) 等 3类 7种模型进行适生区预测，参考李玉春等 (2005) 和胡宜峰等 (2019) 篮选 10 个气候因子 (WorldClim, 1950-2000, 精度为25 arcmin)作为输入 变量: 年平均温度(annual mean temperature, b01)、 最热月最高温(max temperature of warmest month, b05)、最冷月最低温 (min temperature of coldest month, b06)、最湿季度平均温度(mean temperature of wettest quarter, b08)、最干季度平均温度(mean temperature of driest quarter, b09)、最热季度平均温 度(mean temperature of warmest quarter, b10)、年平 均降水量(annual precipitation, b12)、降水季节性 (precipitation seasonality, b15)、最热季度降水量 (precipitation of warmest quarter, b18)和最冷季度降 水量(precipitation of coldest quarter, b19), 着重关注 气候因素对于翼手目适生区的影响。通过ROC曲线 (受试者工作特征曲线)下面积 (area under the receiving operator curve, AUC)、真阳性率 (true positive rate，TPR)、真实技巧统计法(true skill statistic, TSS)和准确率(accuracy)等4项指标篎选最 优模型 (Hallgren et al, 2015), 根据响应曲线 (response curves)明确影响翼手目分布的重要气候 因子。使用最优模型的结果，结合2050年3种碳排放 量预测情景 (representative concentration pathway, RCP) (WorldClim, future projection using Beijing Climate Center Climate System Model, BCC-CSM 1.1, 精度 10 arcmin): RCP 2.6 (最低温室气体排放情 景)、RCP 6.0 (较高温室气体排放情景)和RCP 8.5 (最高温室气体排放情景), 使用投影技术预测在不 同温室气体排放量下罗霄山脉翼手类适生区。 


\section{结果}

\section{1 罗霄山脉翼手目物种多样性}

调查期间共捕获翼手目标本575只, 根据其外 部形态及头骨特征鉴定出菊头蝠科7种, 即中菊头 蝠(Rhinolophus affinis)、华南菊头蝠( $R$. huananus)、

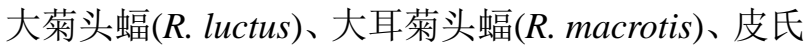
菊头蝠 $(R$. pearsoni)、小菊头蝠 $(R$. pusillus $)$ 和中华菊 头蝠 (R. sinicus); 蹄蝠科 4 种, 即大蹄蝠 (Hipposideros armiger)、中蹄蝠(H. larvatus)、普氏 蹄蝠(H. pratti)和无尾蹄蝠(Coelops frithii); 蝙蝠科 11种, 即中华鼠耳蝠(Myotis chinensis)、渡濑氏鼠耳 蝠(M. rufoniger)、金黄鼠耳蝠(M. formosus)、东亚 水鼠耳蝠(M. petax)、灰伏翼(Hypsugo pulveratus)、 大棕蝠 (Eptesicus serotinus)、中华山蝠 (Nyctalus plancyi)、褐扁妙蝠(Tylonycteris robustula)、斑蝠 (Scotomanes ornatus)、暗褐彩蝠(Kerivoula furva)和 毛翼管鼻蝠(Harpiocephalus harpia); 长翼蝠科1种, 即亚洲长翼蝠(Miniopterus fuliginosus)(图2，表1)。

在基于 $C y t b$ 基因构建的鼠耳蝠属系统发育树 中, 本研究采集到的鼠耳蝠属标本分别与GenBank 中的渡濑氏鼠耳蝠(Myotis refoniger)、西南鼠耳蝠 (M. altarium)、长指鼠耳蝠(M. longipes)、大卫鼠耳 蝠(M. davidii)、华南水鼠耳蝠(M. laniger)、鼠耳蝠1 (Myotis sp. 1)、鼠耳蝠2 (Myotis sp. 2) 和鼠耳蝠3 (Myotis sp. 3) 等序列聚成较高支持率的8个独立支 系(图3A); 在基于COI序列构建的伏翼属系统发育 树中, 本研究所采集到的伏翼属标本与东亚伏翼 (Pipistrellus abramus)、伏翼1 (Pipistrellus sp.1)和伏 翼2 (Pipistrellus sp.2) 聚成较高支持率的3个独立支 系(图3B); 对于管鼻蝠属COI基因系统发生树而言, 其结果显示本研究的管鼻蝠标本与艾氏管鼻蝠 (Murina eleryi)、哈氏管鼻蝠(M. harrisoni)、中管鼻 蝠(M. huttoni)和水甫管鼻蝠(M. shuipuensis)聚成高 支持率的4个独立支系(图3C)。结合通过外部形态以 及头骨特征鉴定出的 23 种, 本研究共采集到38种 (图2)。

另有文献记录但在本次调查中未能采集到的2 种：长尾鼠耳蝠 (Myotis frater)、爪哇伏翼 (Pipistrellus javanicus)(廖文波等, 2014)。结合本研 究采集到的38种, 罗霄山脉现记录翼手目种类4科 14 属 40 种(表1), 其中蝙蝠科种类最多(28种), 占总
数的 $70.0 \%$; 菊头蝠科 7 种，占 $17.5 \%$; 蹄蝠科 4 种， 占 $10.0 \%$; 长翼蝠科最少 $(1$ 种), 占总数的 $2.5 \%$ 。在属 级物种组成上：鼠耳蝠属最多(13种，32.5\%), 其次 是菊头蝠属(Rhinolophus) (7种，17.5\%)、蹄蝠属 (Hipposideros) (4种, 10.0\%)、伏翼属(4种, 10.0\%)、 管鼻蝠属(4种, 10.0\%), 而无尾蹄蝠属(Coelops)、高 级伏翼属(Hypsugo)、棕蝠属(Eptesicus)、山蝠属 (Nyctalus) 、扁乑蝠属 (Tylonycteris)、斑蝠属 (Scotomanes)、毛翼管鼻蝠属(Harpiocephalus)、彩 蝠属(Kerivoula)、长翼蝠属(Miniopterus)最少, 各1 种(2.5\%)。

根据蒋志刚等(2016)评估结果, 无尾蹄蝠、金 黄鼠耳蝠和渡濑氏鼠耳蝠 3 种为易危种, 占总数的 $7.5 \%$; 华南菊头蝠、大菊头蝠、普氏蹄蝠、西南鼠 耳蝠、中华鼠耳蝠、大足鼠耳蝠、爪哇伏翼、灰伏 翼、褐扁颅蝠、亚洲长翼蝠、毛翼管鼻蝠和艾氏管 鼻蝠等 12 种为近危种, 占总数的 $30.0 \%$; 数据缺乏 的种类有5种, 即长尾鼠耳蝠、东亚水鼠耳蝠、哈氏 管鼻蝠、水甫管鼻蝠和暗褐彩蝠，共占12.5\% (表1)。

\section{2 罗霄山脉翼手目分布新记录及分布组成特征}

罗霄山脉现记录的 40 种翼手类动物中, 有 9 种 为近年来发表的省级分布新记录, 即褐扁硕蝠(江 西, 张秋萍等, 2014)、暗褐彩蝠(江西, 李锋等, 2015)、水甫管鼻蝠(江西, 王晓云等, 2016)、中蹄蝠 (湖南, 冯否等, 2017)、大卫鼠耳蝠(湖南, 任锐君等, 2017)、中管鼻蝠(湖北，黄正澜懿等, 2018)、长指 鼠 耳蝠(湖南, 余子寒等, 2018)、毛翼管鼻蝠(江西, 陈 柏承等, 2015; 湖南, 余文华等, 2017; 湖北, 岳阳 等, 2019)、东亚水鼠耳蝠(湖南, 冯否等, 2019), 25 种为罗霄山脉翼手目分布新记录, 如华南菊头蝠、 普氏蹄蝠、大棕蝠等(表1)。

从翼手目的昼间栖息类型看, 罗霄山脉的翼手 目可以分为房屋型(2种, 5.0\%)、洞穴 型(20种, 50.0\%) 和树栖型(18种, $45.0 \%) 3$ 类; 从动物区系划分来看, 主要包括5种分布类型：东洋型(15种, 37.5\%)、南中 国型(8种, 20.0\%)、季风型(2种, 5.0\%)、古北型(3种, $7.5 \%$ )和不易归类分布型(5种, 12.5\%) (表1)。按照不 同山脉汇总结果来看, 万洋山脉翼手目多样性最为 丰富(31种, 77.5\%), 其次是武功山脉(25种, 62.5\%) 和幕阜山脉(11种，27.5\%), 最后是九岭山脉(4种, 10\%) (图4), 诸广山脉则由于调查过程中的天气原 


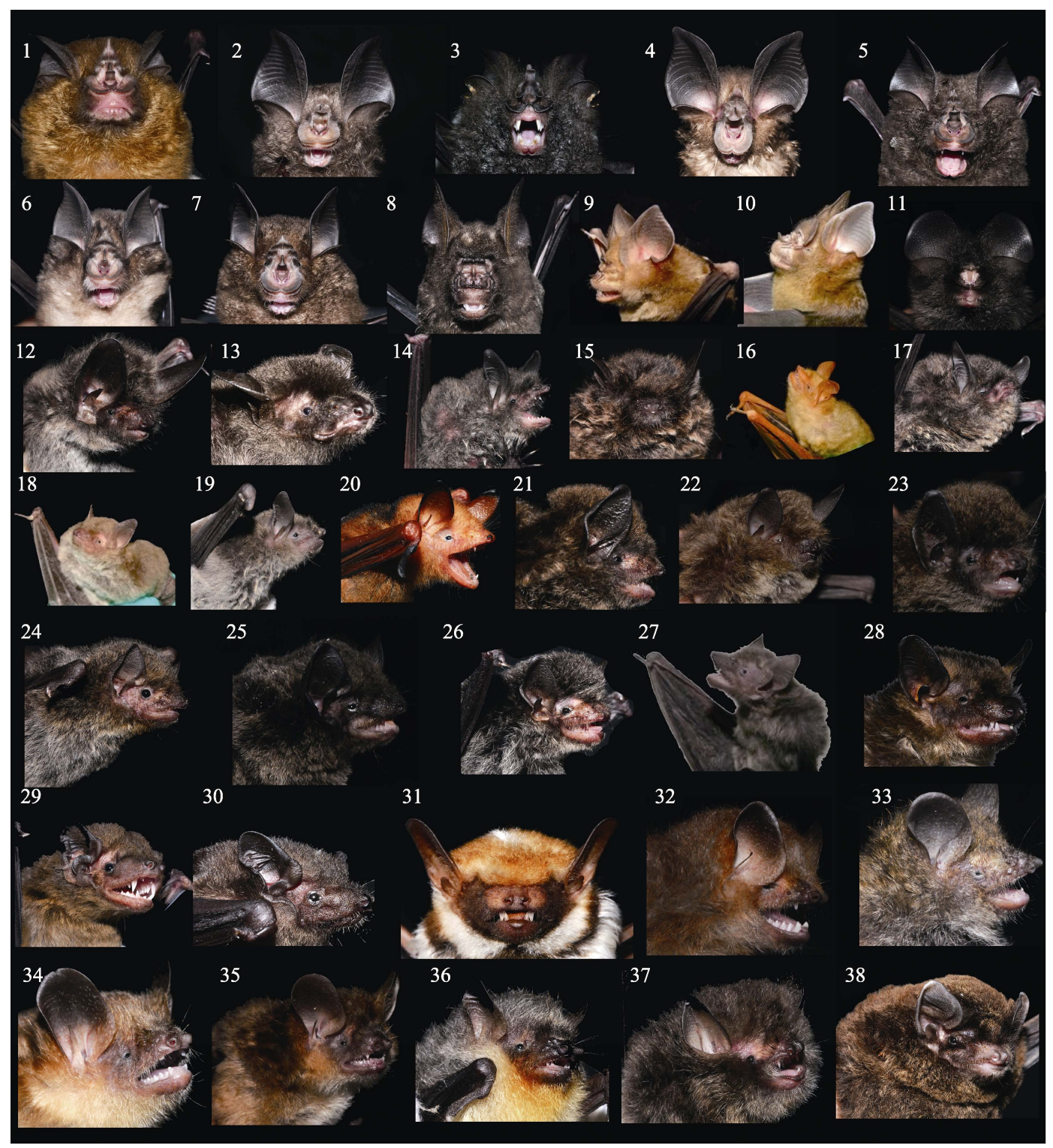

图2 罗霄山脉翼手目物种外形图。 1: 中菊头蝠; 2: 华南菊头蝠; 3: 大菊头蝠; 4: 大耳菊头蝠; 5: 皮氏菊头蝠; 6: 小菊头蝠; 7: 中华菊头蝠; 8: 大蹄蝠; 9: 中蹄蝠; 10: 普氏蹄蝠; 11: 无尾蹄蝠; 12: 西南鼠耳蝠; 13: 中华鼠耳蝠; 14: 长指鼠耳蝠; 15: 大卫鼠耳蝠; 16: 金黄鼠耳蝠; 17: 华南水鼠耳蝠; 18: 东亚水鼠耳蝠; 19: 大足鼠耳蝠; 20: 渡濑氏鼠耳蝠; 21: 鼠耳蝠1; 22: 鼠耳蝠2; 23: 鼠耳蝠3；24：东亚伏翼；25：伏翼1；26：伏翼2；27：灰伏翼；28：大棕蝠; 29：中华山蝠; 30：褐扁颅蝠; 31：斑 蝠; 32: 毛翼管鼻蝠; 33: 艾氏管鼻蝠; 34: 哈氏管鼻蝠; 35: 中管鼻蝠; 36: 水甫管鼻蝠; 37: 暗褐彩蝠; 38: 亚洲长翼蝠。

Fig. 2 Bats sampled from the Luoxiao Mountains. 1, Rhinolophus affinis; 2, Rhinolophus huananus; 3, Rhinolophus luctus; 4, Rhinolophus macrotis; 5, Rhinolophus pearsoni; 6, Rhinolophus pusillus; 7, Rhinolophus sinicus; 8, Hipposideros armiger; 9, Hipposideros larvatus; 10, Hipposideros pratti; 11, Coelops frithii; 12, Myotis altarium; 13, Myotis chinensis; 14, Myotis longipes; 15, Myotis davidii; 16, Myotis formosus; 17, Myotis laniger; 18, Myotis petax; 19, Myotis pilosus; 20, Myotis rufoniger; 21, Myotis sp.1; 22, Myotis sp.2; 23, Myotis sp.3; 24, Pipistrellus abramus; 25, Pipistrellus sp.1; 26, Pipistrellus sp.2; 27, Hypsugo pulveratus; 28, Eptesicus serotinus; 29, Nyctalus plancyi; 30, Tylonycteris robustula; 31, Scotomanes ornatus; 32, Harpiocephalus harpia; 33, Murina eleryi; 34, Murina harrisoni; 35, Murina huttoni; 36, Murina shuipuensis; 37, Kerivoula furva; 38, Miniopterus fuliginosus.

因以及采集工具的限制，目前暂无相关报道。

\section{3 罗霄山翼手目适生区预测}

根据BCCVL在线适生区预测结果：基于随机 森林算法的模型具有更优的预测效果 $(A U C=0.999$;
$\mathrm{TPR}=0.999 ; \mathrm{TSS}=0.999 ;$ Accuracy $=0.999)($ 表2)。 环境因子响应曲线显示降水季节性(b15)、年平均温 度(b01)、年平均降水量(b12)、最冷季度降水量(b19) 对罗霄山脉地区翼手目分布具有重要的影响(图5)。 
表1 罗霄山脉翼手目物种多样性

Table 1 List of Chiroptera diversity in the Luoxiao Mountains

\begin{tabular}{llllll}
\hline 物种 & 分布型 & 濒危等级 & 栖息环境 & 分布区域 & 资料来源 \\
Species & Distribution & Endangered category & Habitat & Location & Sources \\
\hline 菊头蝠科 Rhinolophidae & & & & & \\
1.中菊头蝠 Rhinolophus affinis & $\mathrm{W}$ & LC & 洞穴 Cave & c, d & 标本 Specimen \\
2.华南菊头蝠 Rhinolophus huananus & - & $\mathrm{NT}$ & 洞穴 Cave & c, d & 标本 Specimen \\
3.大菊头蝠 Rhinolophus luctus & $\mathrm{W}$ & $\mathrm{NT}$ & 洞穴 Cave & a, b, c, d & 标本 Specimen \\
4.大耳菊头蝠 Rhinolophus macrotis & $\mathrm{W}$ & LC & 洞穴 Cave & c, d & 标本 Specimen \\
5.皮氏菊头蝠 Rhinolophus pearsoni & $\mathrm{W}$ & LC & 洞穴 Cave & c, d & 标本 Specimen \\
6.小菊头蝠 Rhinolophus pusillus & $\mathrm{S}$ & LC & 洞穴 Cave & a, c, d & 标本 Specimen \\
7.中华菊头蝠 Rhinolophus sinicus & W & LC & 洞穴 Cave & a, b, c, d 标本 Specimen
\end{tabular}

\section{蹄蝠科 Hipposideridae}

8.大蹄蝠 Hipposideros armiger

9.中蹄蝠 Hipposideros larvatus ${ }^{\#}$

10. 普氏蹄蝠 Hipposideros pratti ${ }^{*}$

11.无尾蹄蝠 Coelops frithii

$\begin{array}{ll}\text { W } & \text { LC } \\ \text { W } & \text { LC } \\ \text { W } & \text { NT } \\ \text { W } & \text { VU }\end{array}$

$\begin{array}{ll}\text { 洞穴 Cave } & \text { d } \\ \text { 洞穴 Cave } & \text { c } \\ \text { 洞穴 Cave } & \text { c } \\ \text { 洞穴 Cave } & \text { d }\end{array}$

标本 Specimen

标本 Specimen; Feng et al, 2017

标本 Specimen

标本 Specimen; Xu et al, 2013

\section{蝙蝠科 Vespertilionidae}

12.西南鼠耳蝠 Myotis altarium

13.中华鼠耳蝠 Myotis chinensis

14. 长指鼠耳蝠 Myotis longipes ${ }^{* \#}$

15.大卫鼠耳蝠 Myotis davidii ${ }^{* \#}$

16. 长尾鼠耳蝠 Myotis frater

17. 金黄鼠耳蝠 Myotis formosus"

18. 华南水鼠耳蝠 Myotis laniger*

19. 东亚水鼠耳蝠 Myotis petax

20.大足鼠耳蝠 Myotis pilosus*

21.渡濑氏鼠耳蝠 Myotis rufoniger ${ }^{*}$

22. 鼠耳蝠 1 Myotis sp. $1^{*}$

23. 鼠耳蝠 2 Myotis sp. $2^{*}$

24. 鼠耳蝠 3 Myotis sp. $3^{*}$

25. 东亚伏翼 Pipistrellus abramus

26. 爪哇伏翼 Pipistrellus javanicus

27. 伏翼 1 Pipistrellus sp. $1^{*}$

28. 伏翼 2 Pipistrellus sp.2*

29. 灰伏翼 Hypsugo pulveratus*

30.大棕蝠 Eptesicus serotinus*

31.中华山蝠 Nyctalus plancyi ${ }^{*}$

32. 褐扁乑蝠 Tylonycteris robustula

33. 斑蝠 Scotomanes ornatus* S

34.毛翼管鼻蝠 Harpiocephalus harpia ${ }^{* \#} \mathrm{~W}$

35. 艾氏管鼻蝠 Murina eleryi ${ }^{*}$

36.哈氏管鼻蝠 Murina harrisoni*

37.中管鼻蝠 Murina huttoni ${ }^{* \#}$

38. 水甫管鼻蝠 Murina shuipuensis ${ }^{*}$

39.暗褐彩蝠 Kerivoula furva ${ }^{* \#}$

$\begin{array}{ll}\text { S } & \text { NT } \\ \text { U } & \text { NT } \\ \text { O } & \text { LC } \\ \text { E } & \text { LC } \\ \text { O } & \text { DD } \\ \text { S } & \text { VU } \\ \text { O } & \text { LC } \\ \text { O } & \text { DD } \\ \text { U } & \text { NT } \\ \text { S } & \text { VU } \\ - & - \\ - & - \\ - & - \\ \text { E } & \text { LC } \\ \text { S } & \text { NT } \\ - & - \\ - & - \\ \text { S } & \text { NT } \\ \text { U } & \text { LC } \\ \text { S } & \text { LC } \\ \text { W } & \text { NT } \\ \text { S } & \text { LC } \\ \text { W } & \text { NT } \\ \text { W } & \text { NT } \\ \text { W } & \text { DD } \\ \text { W } & \text { LC } \\ - & \text { DD } \\ \text { W } & \text { DD }\end{array}$

$\begin{array}{lll}\text { 洞穴 Cave } & \text { c, d } & \text { 标本 Specimen } \\ \text { 洞穴 Cave } & \text { a } & \text { 标本 Specimen } \\ \text { 洞穴 Cave } & \text { c, d } & \text { 标本 Specimen; Yu et al, 2018 } \\ \text { 洞穴 Cave } & \text { a, b, c, d } & \text { 标本 Specimen; Ren et al, 2017 } \\ \text { 洞穴 Cave } & \text { c, d } & \text { Liao et al, 2014 } \\ \text { 森林 Forest } & \text { c } & \text { 标本 Specimen } \\ \text { 森林 Forest } & \text { c, d } & \text { 标本 Specimen } \\ \text { 洞穴 Cave } & \text { c } & \text { 标本 Specimen; Feng et al, 2019 } \\ \text { 洞穴 Cave } & \text { c } & \text { 标本 Specimen } \\ \text { 洞穴 Cave } & \text { d } & \text { 标本 Specimen } \\ \text { 森林 Forest } & \text { d } & \text { 标本 Specimen } \\ \text { 森林 Forest } & \text { d } & \text { 标本 Specimen } \\ \text { 森林 Forest } & \text { d } & \text { 标本 Specimen } \\ \text { 房屋 House } & \text { a, d } & \text { 标本 Specimen } \\ \text { 森林 Forest } & \text { d } & \text { Liao et al, 2014 } \\ \text { 森林 Forest } & \text { c, d } & \text { 标本 Specimen } \\ \text { 森林 Forest } & \text { d } & \text { 标本 Specimen } \\ \text { 森林 Forest } & \text { c } & \text { 标本 Specimen } \\ \text { 森林 Forest } & \text { a } & \text { 标本 Specimen } \\ \text { 房屋 House } & \text { d } & \text { 标本 Specimen } \\ \text { 森林 Forest } & \text { c, d } & \text { 标本 Specimen; Zhang et al, 2014 } \\ \text { 森林 Forest } & \text { a } & \text { 标本 Specimen } \\ \text { 森林 Forest } & \text { a, c, d } & \text { 标本 Specimen; Chen et al, 2015; } \\ & & \text { Yu et al, 2017; Yue et al, 2019 } \\ \text { 森林 Forest } & \text { c, d } & \text { 标本 Specimen } \\ \text { 森林 Forest } & \text { d } & \text { 标本 Specimen } \\ \text { 森林 Forest } & \text { a, b, c, d } & \text { 标本 Specimen; Huang et al, 2018 } \\ \text { 森林 Forest } & \text { d } & \text { 标本 Specimen; Wang et al, 2016 } \\ \text { 森林 Forest } & \text { c, d } & \text { 标本 Specimen; Li et al, 2015 } \\ & & \end{array}$

长翼蝠科 Miniopteridae

40.亚洲长翼蝠 Miniopterus fuliginosus O

NT

山洞 Cave a, c, d 标本 Specimen

(1)分布型(张荣祖, 1999): W: 东洋型; S: 南中国型; E: 季风型; U: 古北型; O: 不易归类, 分布较广; “一”表示缺少数据; (2)濒危等级(中国脊椎 动物红色名录, 蒋志刚等, 2016): VU: 易危; NT: 近危; LC: 无危; DD: 数据缺乏; (3)* 罗霄山分布新记录; \# 省级分布新记录; (4)分布区域: a: 幕阜山脉; b: 九岭山脉; c: 武功山脉; d: 万洋山脉。

(1)Distribution: W, Oriental realm; S, South China region; E, Monsoon type; U, Palearctic realm (Zhang, 1999); O, Difficult to categorize with wide distribution; “-”, missing data; (2)Endangered category (Red list of China’s Vertebrates, Jiang et al, 2016): VU, Vulnerable; NT, Near threatened; LC, Least concern; DD, Data deficient; (3)* New record of the Luoxiao Mountains; \# New record of province; (4)Location: a, Mufu Mountains; b, Jiuling Mountains; c, Wugong Mountains; d, Wanyang Mountains. 

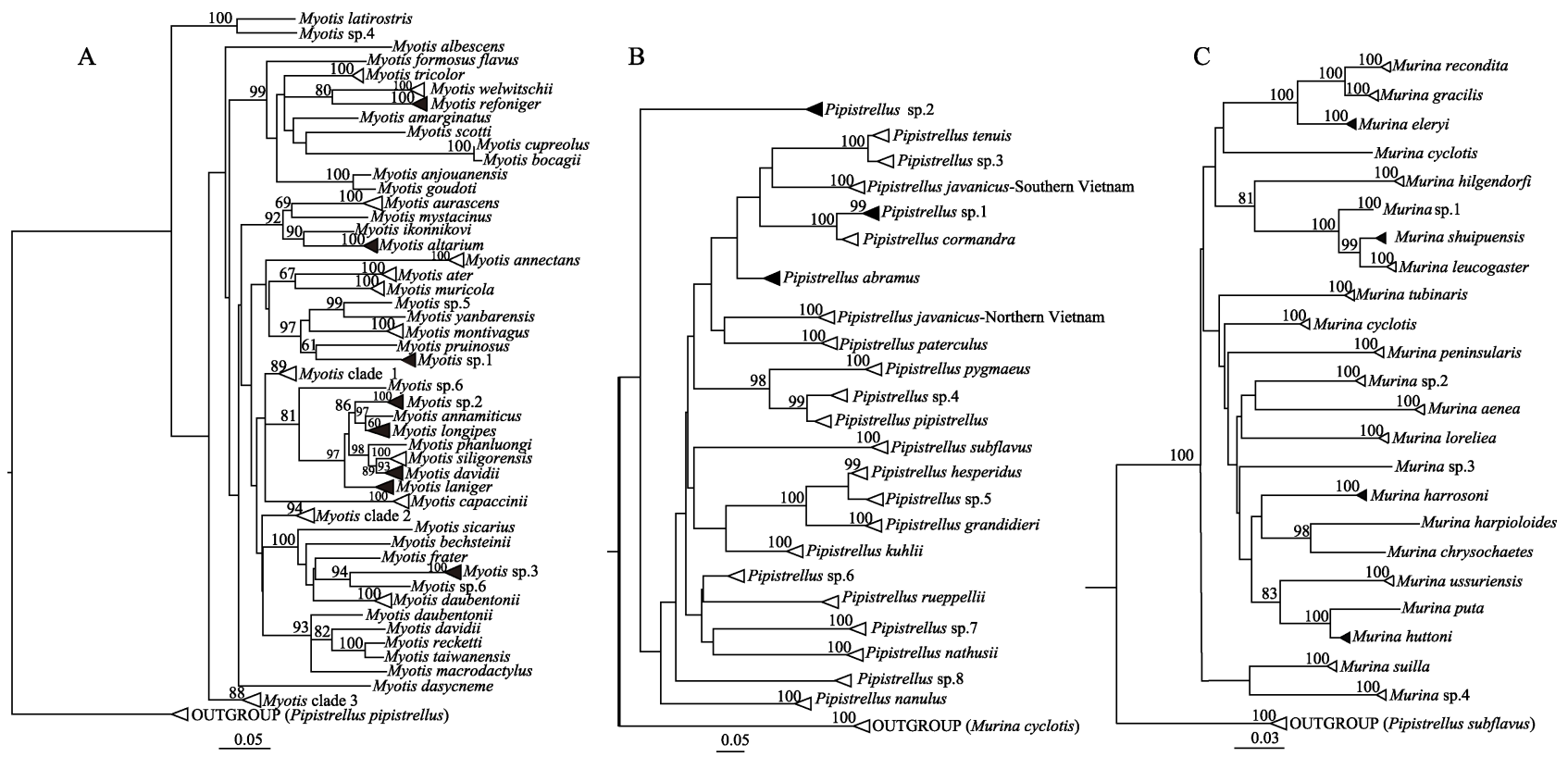

图3 罗霄山脉鼠耳蝠、伏翼和管鼻蝠三属系统发生树。A：基于线粒体 Cyt $b$ 基因构建的鼠耳蝠属最大似然树; B: 基于线粒 体COI基因构建的伏翼属最大似然树; C: 基于线粒体COI基因构建的管鼻蝠属最大似然树。

Fig. 3 Phylogenetic tree of three genera Myotis, Pipistrellus and Murina in the Luoxiao Mountains. A, Maximum likelihood tree of Myotis based on Cyt b gene; B, Maximum likelihood tree of Pipistrellus based on COI gene; C, Maximum likelihood tree of Murina based on COI gene.

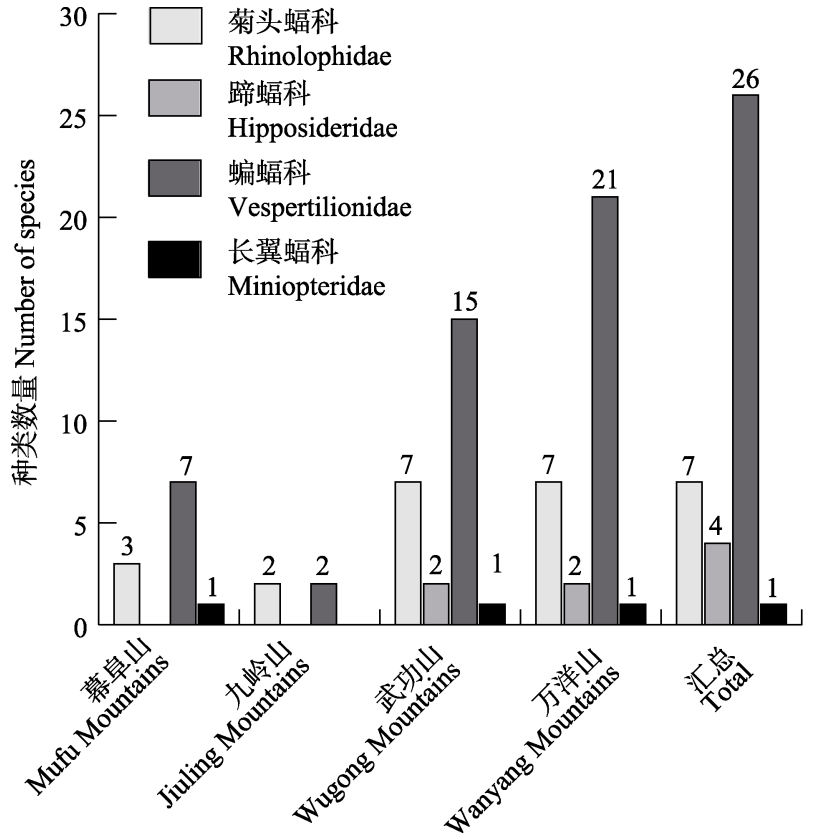

图4 罗霄山脉不同山脉翼手目物种多样性

Fig. 4 Chiroptera species diversity in different mountains of the Luoxiao Mountains

此外，随机森林模型预测结果显示，罗霄山脉中部 及南部为翼手目高适生区(适生性 $\geq 50 \%$ ), 面积约 为罗霄山脉的30\% (图6a), 是该类群保护工作的重 要现场。
基于随机森林模型的生境预测结果, 本研究对 2050年3种不同的碳排放情景下罗霄山脉翼手目适 生区进行了预测。结果显示: RCP 2.6情景下(最低温 室气体排放情景) 2050年罗霄山脉翼手目适生区(适 生性 $\geq 50 \%$ )将增加至该区域总面积的35\% (图6b); 但在RCP 6.0情景下(较高温室气体排放情景), 适生 区(适生性 $\geq 50 \%$ ) 将明显收缩，其面积约为整个罗 霄山脉的 $10 \%$, 且主要集中于武功山脉和九岭山脉 (图6c); 在RCP 8.6情景下(最高温室气体排放情景), 适生区(适生性 $\geq 50 \%$ ) 将急剧收缩, 面积仅约为整 个罗霄山脉的 $5 \%$, 且主要集中于武功山脉(图6d)。 相比现今适生区, 后两种情景下罗霄山脉翼手目适 生区均有往山区缩减和北部迁移的趋势(图6)。

\section{3 论讨}

罗霄山脉是北半球亚热带东段陆地生物南北 向迁徙、扩散的重要通道, 为生物多样性富集区(张 荣祖, 1999; 廖文波等, 2014; 魏识广等, 2015; 宫辉 力等, 2016)。目前, 罗霄山脉记录到翼手目 14 属40 种, 其中以东洋型和南中国型物种为主, 具较强的 华中区一华南区特点，但也存在西南区成分的渗透; 从濒危等级上可以看出，除 5 个未定种无法确定等 
表2 不同适生区预测模型之间的预测效果对比

Table 2 Habitat distribution prediction analysis from different models

\begin{tabular}{|c|c|c|c|c|c|c|c|}
\hline & \multirow{2}{*}{$\begin{array}{l}\text { 框架模型 Profile models } \\
\text { Bioclim }\end{array}$} & \multicolumn{2}{|c|}{ 机器学习模型 } & \multicolumn{2}{|c|}{ Machine learning models } & \multicolumn{2}{|c|}{ 统计回归模型 Statistical models } \\
\hline & & ANN & CT & MaxEnt & $\mathrm{RF}$ & FDA & GLM \\
\hline 真阳性率 True positive rate & 0.999 & 0.998 & 0.833 & 0.944 & 0.999 & 0.972 & 0.917 \\
\hline 真实技巧统计法 True skill statistic & 0.889 & 0.998 & 0.750 & 0.896 & 0.999 & 0.917 & 0.917 \\
\hline 准确度 Accuracy & 0.944 & 0.998 & 0.875 & 0.951 & 0.999 & 0.958 & 0.958 \\
\hline $\begin{array}{l}\text { 受试者特征曲线下面积 } \\
\text { Area under the reciving opera }\end{array}$ & 0.970 & 0.998 & 0.880 & 0.970 & 0.999 & 0.980 & 0.980 \\
\hline
\end{tabular}

Bioclim: 框架模型; ANN: 人工神经网络模型; CT: 决策树算法; MaxEnt: 最大熵模型; RF: 随机森林算法; FDA: 多变量自适应回归样条算 法; GLM: 广义线性模型。

Bioclim, Profile models; ANN, Artificial neural network; CT, Classification tree; MaxEnt, Maximum entropy; RF, Random forest; FDA, Flexible discriminant analysis; GLM, Generalized linear model.
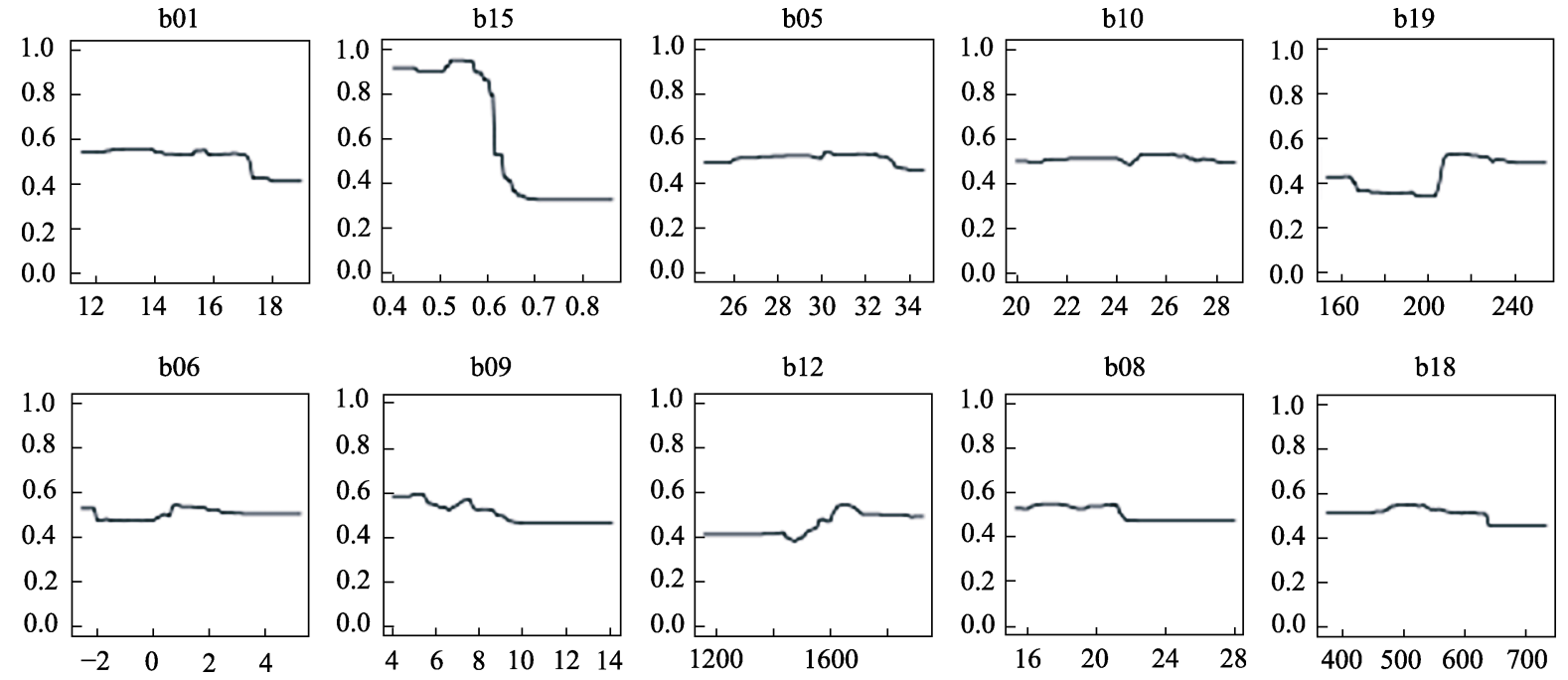

图5 随机森林算法的响应曲线。 b01: 年平均温度; b15: 降水季节性; b05: 最热月最高温; b10: 最热季度平均温度; b19: 最 冷季度降水量; b06: 最冷月最低温; b09: 最干季度平均温度; b12: 年平均降水量; b08: 最湿季度平均温度; b18: 最热季度 降水量。

Fig. 5 Response curves for random forest. b01, Annual mean temperature; b15, Precipitation seasonality; b05, Max temperature of warmest month; b10, Mean temperature of warmest quarter; b19, Precipitation of coldest quarter; b06, Min temperature of coldest month; b09, Mean temperature of driest quarter; b12, Annual precipitation; b08, Mean temperature of wettest quarter; b18, Precipitation of warmest quarter.
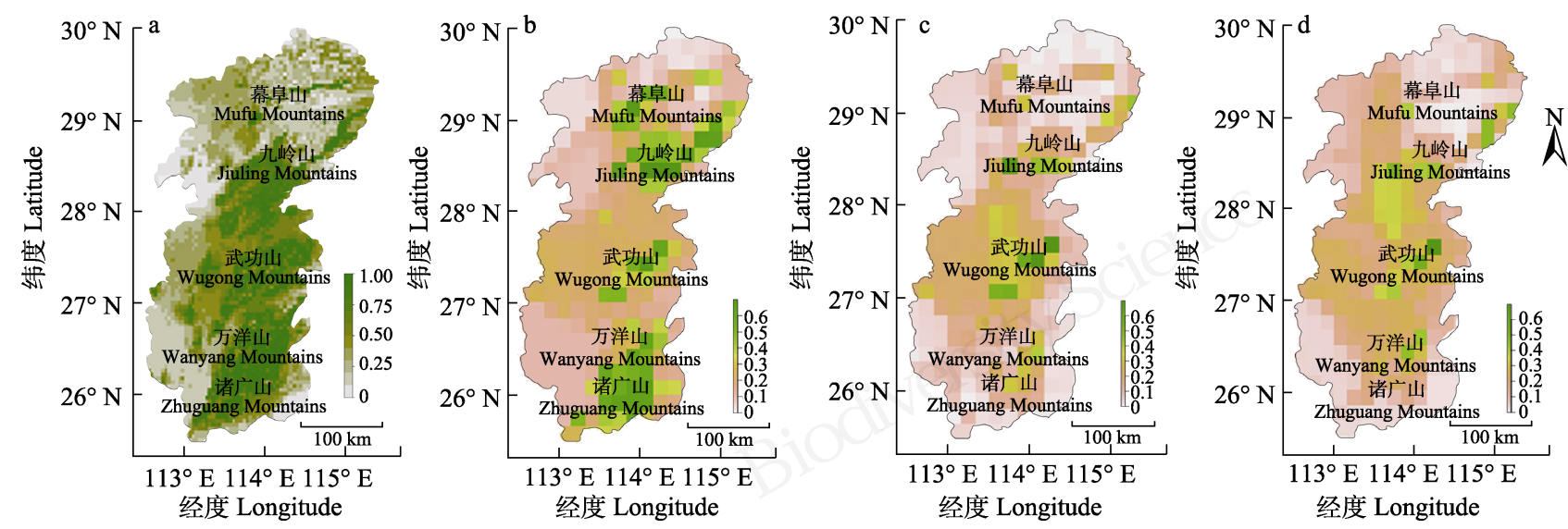

图6 罗霄山脉翼手目分布生境预测。a: 当前环境下; b: 2050年RCP 2.6情景下; c: 2050年RCP 6.0情景下; d: 2050年RCP 8.6 情景下。

Fig. 6 Suitable habitat distribution predictions of Chiroptera in the Luoxiao Mountains. a, Present; b, RCP 2.6-2050; c, RCP 6.0-2050; d, RCP 8.5-2050. 
级外, 罗霄山脉翼手目有易危(VU)物种3种、近危 (NT)物种 12 种和数据缺乏(DD)物种 5 种, 共 20 种, 占罗霄山脉翼手目种类的 $50.0 \%$ 。本研究实际调查 与蒋志刚等(2016)在全国尺度上对翼手目濒危等级 评估结果基本一致, 如3种易危(VU)等级蝙蝠(无尾 蹄蝠、金黄鼠耳蝠和渡濑氏鼠耳蝠), 在罗霄山脉极 难发现, 野外调查数量极少; 大多数无危(LC)等级 翼手目物种在罗霄山脉具有较稳定的种群数量, 且 分布范围也相对较广。但我们发现评估为无危(LC) 等级的中蹄蝠和大棕蝠, 在罗霄山脉5年的实地调 查中极少发现，而评估为“数据缺乏”等级的哈氏管 鼻蝠、水甫管鼻蝠和暗褐彩蝠在罗霄山脉却有一定 的种群数量, 特别是暗褐彩蝠在竹林环境数量稳 定。这种不同尺度上的差异表明, 我国翼手目物种 多样性调查尚待加强, 濒危等级评估有待进一步修 订、补充和完善。同时, 也表明罗霄山脉翼手目资 源较为丰富, 对罗霄山脉翼手目资源(特别是森林 树栖型蝙蝠)的专项研究及保护有待开展。

早期翼手目本底调查受采集工具的限制, 主要 集中于洞穴型蝙蝠类群, 本次调查中新使用了蝙蝠 坚琴网, 采集到树栖型蝙蝠18种, 占罗霄山脉翼手 目种类的 $45.0 \%$, 在罗霄山脉原仅有 1 种森林型蝙蝠 (廖文波等, 2014)的基础上增加了17种，丰富了其翼 手目物种的多样性。而森林型蝙蝠种类大多为易 危、近危以及数据缺乏等级(共 9 种), 是翼手目研究 及保护中不可或缺的类群。同时在调查中也发现褐 扁颅蝠、暗褐彩蝠、水甫管鼻蝠、中蹄蝠、大卫鼠 耳蝠、中管鼻蝠、长指鼠耳蝠、毛翼管鼻蝠、东亚 水鼠耳蝠 9 个省级新记录, 以及 25 种罗霄山脉分布 新记录，另有3种鼠耳蝠(Myotis sp.1、Myotis sp.2、 Myotis sp.3)和2种伏翼(Pipistrellus sp.1、Pipistrellus sp.2)为待定种, 均证实了罗霄山脉地区具有较高的 翼手目多样性, 也与纪维红和陈服官(1990)、李 春 等(2005)提出的海南岛、台湾、罗霄山脉以及武陵 山脉都具有较高分布密度的结论相吻合。目前, 海 南岛(8科20属41种; 胡宜峰等, 2018)、台湾(6科21 属33种; 郑锡奇等, 2015)、武陵山脉(4科16属39种; 张佩玲等, 2019)以及罗霄山脉(本研究, 4科14属40 种)等热点区域均相继被证实, 可加深对中国区域 翼手目地理分布格局与历史进程的理解(李迪强和 宋延龄, 2000)。

同时，罗霄山脉翼手目的适生区预测结果显示，
当前环境下翼手目分布热点区主要集中于罗霄山 脉核心区域。在影响蝙蝠分布的重要环境因素方面, 李玉春等(2005)和胡宜峰等(2019)均发现年平均温 度、年平均降水量、海拔、最热季度平均温度、最 热月最高温为影响翼手目分布的重要环境因素, 本 研究的结果也与之相符。我们认为年均温度与蝙蝠 的温度耐受性，区域的植被类型、生长与组成相关， 进而影响蝙蝠的新陈代谢速率、冬眠栖息地选择以 及生殖期时间(Webb et al, 1995; Rebelo et al, 2010); 而年平均降水量则与局部植被特征及昆虫的发育 相关，潜在性影响蝙蝠的食物组成与丰富度 (Bronrier et al, 1999; 李玉春等, 2005; Arthur et al, 2014)。

温室气体的持续排放导致全球性气候急剧变 化(Griffiths et al, 2005; Rusticucci, 2012), 因此预测 其影响的范围与程度具有重要的生物保护意义 (Solomon et al, 2007)。而温室气体排放量(RCP)是一 项重要的评估指标(Moss et al, 2010), 胡婷等(2017) 指出在3种不同情景(RCP 2.6、RCP 6.0、RCP 8.5)下 2050年中国年均温将激增 $1.9^{\circ} \mathrm{C} 、 2.9^{\circ} \mathrm{C}$ 与 $5.5^{\circ} \mathrm{C}$, 年均 降水量分别增加 $0.12 \mathrm{~mm} / \mathrm{d} 、 0.21 \mathrm{~mm} / \mathrm{d} 、 0.32 \mathrm{~mm} / \mathrm{d}$, 与古温度在较长时间尺度上的变化相比, 这种短期 急剧变化极易引起气候整体性剧变、增加极端气候 事件发生的频率，最终引起生态灾难(Voigt \& Kingston, 2016; Foster et al, 2017)。本研究结果提示: 在RCP 2.6情景下(最低温室气体排放情景), 2050年 罗霄山脉翼手目适生区较当前情况下有所扩大(约 16.7\%), 这可能得益于温度上升及降水量缓慢增加, 热带向两极延伸，植被类型增加，多样性提高，翼 手目的种群数量增加并向四周扩散所致, 但其物种 多样性是否增加仍不明确; 在另外两种较高温室气 体排放情景下，由于气温急速升高，翼手目适生区 将受到挤压而急剧减少 (RCP 6.0情景下减少约 66.7\%, RCP 8.6情景下约减少 83.3\%), 蝙蝠将向武 功山脉以及万洋山脉迁移以躲避不良环境(图6), 而 适生区的迁移、减少与重叠必然导致种内与种间竞 争的加剧，增加部分物种短期灭绝的风险; 同时, 温度的升高和相关生存压力的快速产生可导致蝙 蝠这一类群的性别比例扭曲与蝙蝠种类组成和数 量的变化 (Cameron，2004; Adams，2010，2017; Adams \& Hayes, 2018)。目前, 蝙蝠作为哺乳动物中 的第二大类群，具有极为重要的生态作用，包括： 
害虫防控、传授花粉、通过食物网加速生态系统的 物质循环与能量流动, 生态价值极大(Law, 1996; Walsh \& Morton, 2009; Fenton \& Simmons, 2014; Maine \& Boyles, 2015), 因此该类群的种类和数量 急剧变化无疑将会对罗霄山脉的生态系统造成难 以预测的影响(Williamsguillén et al, 2008; Kunz et al, 2011)。

此外, 蝙蝠是多种致病病毒的天然宿主, 当前 已知的如埃博拉病毒(Ebola virus)会出现在部分食 果蝙蝠中 (Epomophorus wahlbergi、Hypsignathus monstrosus等)、乙型冠状病毒SARS (Severe Acute Respiratory Syndrome virus)会出现在部分菊头蝠类 群中(中华菊头蝠、大耳菊头蝠、皮氏菊头蝠等)以 及狂犬病病毒(Rabies virus)会出现在绝大多数蝙蝠 类群中(Calisher et al, 2006; Daszak, 2010; Wong et al, 2010; Olival et al, 2017), 因此, 完善翼手目本底信 息以及未来分布区的预测无疑对该类群的保护管 理和疾病防控有重要的参考意义。

致谢: 感谢江西井冈山国家级自然保护区、湖南桃 源洞国家级自然保护区等在野外调查中给予的支 持与帮助。感谢广州大学S Sanjan Thapa博士在论文 撰写及部分标本鉴定中的帮助，感谢湖南师范大学 冯否及华中师范大学曹阳在野外调查及数据收集 上提供的帮助和建议, 感谢各校部分本科生参与野 外科考及室内标本鉴定和制作等工作。

\section{参考文献}

Adams RA (2010) Bat reproduction declines when conditions mimic climate change projections for western North America. Ecology, 91, 2437-2445.

Adams RA (2017) Dark side of climate change: Speciesspecific responses and indications of disruption in spring altitudinal migration in Myotis bats. Journal of Zoology, 304, 1-7.

Adams RA, Hayes MA (2018) Assemblage-level analysis of sex-ratios in Coloradan bats in relation to climate variables: A model for future exceptions. Global Ecology and Conservation, 14, e00379.

Arthur L, Lemaire M, Dufrene L, Viol IL, Julien JF, Kerbiriou C (2014) Understanding bat-habitat associations and the effects of monitoring on long-term roost success using a volunteer dataset. Acta Chiropterologica, 16, 397-411.

Bates PJJ, Harrison DL (1997) Bats of the Indian Subcontinent. Harrison Zoological Museum Publication, Sevenoaks.
Boyles JG, Cryan PM, McCracken GF, Kunz TH (2011) Economic importance of bats in agriculture. Science, 332, 41-42.

Bronrier GN, Maloney SK, Buffenstein R (1999) Survival tactics within thermally-challenging roosts: Heat tolerance and cold sensitivity in the Angolan free-tailed bat, Mops condylurus. South African Journal of Zoology, 34, 1-10.

Calisher CH, Childs JE, Field HE, Holmes KV, Schountz T (2006) Bats: Important reservoir hosts of emerging viruses. Clinical Microbiology Reviews, 19, 531-545.

Cameron EZ (2004) Facultative adjustment of mammalian sex ratios in support of the Trivers-Willard hypothesis: Evidence for a mechanism. Proceedings of the Royal Society B: Biological Sciences, 271, 1723-1728.

Chen BC, Yu WH, Wu Y, Li F, Xu ZX, Zhang QP, Harada M, Motokawa M, Peng HY (2015) New record and sexual dimorphism of Harpiocephalus harpia in Guangxi and Jiangxi, China. Sichuan Journal of Zoology, 34, 211-215, 222. (in Chinese with English abstract) [陈柏承, 余文华, 吴毅, 李锋, 徐忠鲜, 张秋萍, 原田正史, 本川雅治, 彭 红元 (2015) 毛翼管鼻蝠在广西和江西分布新纪录及其 性二型现象. 四川动物, 34, 211-215, 222.]

Cheng HC, Fang YP, Chou CH (2015) A Photographic Guide to the Bats of Taiwan, 2nd edn. Endemic Species Research Institute, Taizhong. (in Chinese) [郑锡奇, 方引平，周政翰 (2015) 台湾蝙蝠图鉴(第2版). “行政院农业委员会”特有 生物研究保育中心, 台中.]

Dang FH, Yu WH, Wang XY, Guo WJ, Zhuang ZS, Mei TY, Zhang QP, Li F, Li YC (2016) Taxonomic clarification of Myotis rufoniger from China. Sichuan Journal of Zoology, 36, 7-13. (in Chinese with English abstract) [党飞红, 余文 华, 王晓云, 郭伟健, 庄卓生, 梅廷媛, 张秋萍, 李锋, 李 玉春 (2016) 中国渡濑氏鼠耳蝠种名订正. 四川动物, 36, 7-13.]

Daszak P (2010) Bats, in black and white. Science, 329, 634-635.

Ding TM, Wang ZY (1989) Scotomanes ornatus found in Jinggangshan Nature Reserve. Jiangxi Forestry Science and Technology, (1), 32. (in Chinese) [丁铁明, 王作义 (1989) 井冈山自然保护区发现斑蝠. 江西林业科技, (1), 32.]

Drummond MJ, McCarthy JJ, Sinha M, Spratt HM, Volpi E, Esser KA, Rasmussen BB (2011) Aging and microRNA expression in human skeletal muscle: A microarray and bioinformatics analysis. Physiological Genomics, 43, 595-603.

Edgar RC (2004) MUSCLE: Multiple sequence alignment with high accuracy and high throughput. Nucleic Acids Research, 32, 1792-1797.

Feng L, Wu QQ, Shi SC, Ren RJ, Liu YM, Yu ZH, Deng XJ (2017) Morphostructure and phylogenesis of Horsfield's leaf-nosed bat (Hipposideros larvatus) from Hunan Province. Life Science Research, 21, 515-518. (in Chinese with English abstract) [冯否, 吴倩倩, 石胜超, 任锐君, 刘 
宜敏, 余子寒, 邓学建 (2017) 湖南发现的中蹄蝠形态结 构及系统发育研究. 生命科学研究, 21, 515-518.]

Feng L, Wu QQ, Yu ZH, Liu Z, Deng XJ, Liu Y (2019) Eastern Daubenton's myotis (Myotis petax) discovered in Hengdong County, Hunan Province. Chinese Journal of Zoology, 54, 22-29. (in Chinese with English abstract) [冯 砧, 吴倩倩, 余子寒, 刘钊, 邓学建, 柳勇 (2019) 湖南 衡东发现东亚水鼠耳蝠. 动物学杂志, 54, 22-29.]

Fenton MB, Simmons NB (2014) Bats: A World of Science and Mystery. University of Chicago Press, Chicago.

Foster GL, Royer DL, Lunt DJ (2017) Future climate forcing potentially without precedent in the last 420 million years. Nature Communications, 8, 14845.

Gong HL, Zhuang WY, Liao WB (2016) Comprehensive scientific investigation on biodiversity in Luoxiao Mountains. China Science and Technology Achievements, 17(22), 9-10. (in Chinese) [宫辉力, 庄文颖, 廖文波 (2016) 罗霄山脉地区生物多样性综合科学考察. 科技计 划成果, 17(22), 9-10.]

Griffiths GM, Chambers LE, Haylock MR, Manton MJ, Nicholls N, Baek HJ, Choi Y, Dellamarta PM, Gosai A, Iga N, Lata R, Laurent V, Mairtrepierre L, Nakamigawa H, Ouprasitwong N, Solofa D, Tahani L, Thuy DT, Tibig L, Trewin B, Vediapan K, Zhai P (2005) Change in mean temperature as a predictor of extreme temperature change in the Asia-Pacific region. International Journal of Climatology, 25, 1301-1330.

Guo XC, Lu GJ, Sun KP, Huang GS, Feng J (2010) Characteristics of echolocation call and morphology of five sympatric bats species. Journal of Jiangxi Normal University (Natural Science), 34, 84-88. (in Chinese with English abstract) [郭新春, 卢冠军, 孙克萍, 黄赣生, 冯江 (2010) 5 种共栖蝙蝠的形态和回声定位声波特征. 江西师范大学 学报(自然科学版), 34, 84-88.]

Hallgren W, Beaumont L, Bowness A, Chambers L, Graham E, Holewa H, Laffan S, Mackey B, Nix H, Price J, Vanderwal J, Warren R, Weis G (2015) The Biodiversity and Climate Change Virtual Laboratory: Where ecology meets big data. Environmental Modeling \& Software, 76, 182-186.

Hu T, Sun Y, Zhang XB (2017) Temperature and precipitation projection at 1.5 and $2^{\circ} \mathrm{C}$ increase in global mean temperature. Chinese Science Bulletin, 62, 3098-3111. (in Chinese with English abstract) [胡婷, 孙颖, 张学斌 (2017) 全球 1.5 和 $2^{\circ} \mathrm{C}$ 温升时的气温和降水变化预估. 科 学通报, 62, 3098-3111.]

Hu YF, Yu WH, Yue Y, Huang ZLY, Li YC, Wu Y (2019) Species diversity and potential distribution of Chiroptera on Hainan Island, China. Biodiversity Science, 27, 400-408. (in Chinese with English abstract) [胡宜峰, 余文华, 岳阳, 黄 正澜懿, 李玉春, 吴毅 (2019) 海南岛翼手目物种多样性 现状与分布预测. 生物多样性, 27, 400-408.]

Huang ZLY, Hu YF, Wu H, Cao Y, Liu BQ, Zhou JJ, Wu Y, Yu WH (2018) New distribution record of Murina huttoni in
Hubei and Zhejiang provinces. Journal of West China Forestry Science, 47(6), 73-77. (in Chinese with English abstract) [黄正澜懿, 胡宜峰, 吴华, 曹阳, 刘宝权, 周佳 俊, 吴毅, 余文华 (2018) 中管鼻蝠在湖北和浙江的分布 新纪录. 西部林业科学, 47(6), 73-77.]

Ji WH, Chen FG (1990) The relationship between the species density of Chiroptera and environmental factor. Acta Theriologica Sinica, 10, 23-30. (in Chinese with English abstract) [纪维红, 陈服官 (1990) 翼手目物种密度分布 与环境因素的关系. 兽类学报, 10, 23-30.]

Jiang TL, Feng J, Sun KP, Zhao YJ, Zhang ZZ (2007) A new record of the Chiroptera in Jiangxi Province-Myotis formosus. Acta Theriologica Sinica, 27, 203-205. (in Chinese with English abstract) [江廷磊, 冯江, 孙克萍, 赵 云蛟, 张桢珍 (2007) 江西省翼手目新纪录一一绯鼠耳 蝠. 兽类学报, 27, 203-205.]

Jiang ZG, Jiang JP, Wang YZ, Zhang E, Zhang YY, Li LL, Xie F, Cai B, Cao L, Zheng GM, Dong L, Zhang ZW, Ding P, Luo ZH, Ding CQ, Ma ZJ, Tang SH, Cao WX, Li CW, Hu HJ, Ma Y, Wu Y, Wang YX, Zhou KY, Liu SY, Chen YY, Li JT, Feng ZJ, Wang Y, Wang B, Li C, Song XL, Cai L, Zang CX, Zeng Y, Meng ZB, Fang HX, Ping XG (2016) Red List of China's Vertebrates. Biodiversity Science, 24, 500-551. (in Chinese and in English) [蒋志刚, 江建平, 王 跃招, 张鹗, 张雁云, 李立立, 谢锋, 蔡波, 曹亮, 郑光 美, 董路, 张正旺, 丁平, 罗振华, 丁长青, 马志军, 汤宋 华, 曹文宣, 李春旺, 胡慧建, 马勇, 吴毅, 王应祥, 周开 亚, 刘少英, 陈跃英, 李家堂, 冯祚建, 王燕, 王斌, 李 成, 宋雪琳, 蔡蕾, 蔵春金金, 曾岩, 孟智斌, 方红霞, 平晓 鸽 (2016) 中国脊椎动物红色名录. 生物多样性, 24, 500-551.]

Kunz TH, Torrez EBD, Bauer D, Lobova T, Fleming TH (2011) Ecosystem services provided by bats. Annals of the New York Academy of Science, 1223, 1-38.

Law BS (1996) The ecology of bats in south-east Australian forests and potential impacts of forestry practices: A review. Pacific Conservation Biology, 2, 363-374.

Li DQ, Song YL (2000) Review on hot spot and GAP analysis. Chinese Biodiversity, 8, 208-214. (in Chinese with English abstract) [李迪强, 宋延龄 (2000) 热点地区与GAP分析 研究进展. 生物多样性, 8, 208-214.]

Li F, Yu WH, Wu Y, Chen BC, Zhang QP, Xu ZX, Wang YY, Chen CQ, Harada M (2015) Kerivoula titania discovered in Jiangxi Province, China. Chinese Journal of Zoology, 50, 1-8. (in Chinese with English abstract) [李锋, 余文华, 吴 毅, 陈柏承, 张秋萍, 徐忠鲜, 王英永, 陈春泉, 原田正 史 (2015) 江西省发现泰坦尼亚彩蝠. 动物学杂志, 50, 1-8.]

Li YC, Meng YH, Zhang LC, Ye Q (2005) Analysis of environmental factors on geographical distribution of Chinese Chiroptera. Acta Zoologica Sinica, 51, 413-422. (in Chinese with English abstract) [李玉春, 蒙以航, 张利存, 叶青 (2005) 中国翼手目地理分布的环境因子影响分析. 
动物学报, 51, 413-422.]

Liao WB, Wang L, Wang YY, Liu WQ, Jia FL, Shen HX, Fan Q, Li QH, Yang SL (2018) Study on Biodiversity of the Taoyuandong National Nature Reserve in Hunan Province. Science Press, Beijing. (in Chinese) [廖文波, 王蕾, 王英 永, 刘蔚秋, 贾风龙, 沈红星, 凡强, 李秦辉, 杨树林 (2018) 湖南桃源洞国家级自然保护区生物多样性综合科 学考察. 科学出版社, 北京.]

Liao WB, Wang YY, Li Z, Peng SL, Chen CQ, Fan Q, Jia FL, Wang L, Liu WQ, Yin GS, Shi XG, Zhang DD (2014) Integrated Study on Biodiversity of Mount Jinggangshan Regions in China. Science Press, Beijing. (in Chinese) [廖文 波, 王英永, 李贞, 彭少麟, 陈春泉, 凡强, 贾凤龙, 王 蕾, 刘蔚秋, 尹国胜, 石祥刚, 张丹丹 (2014) 中国井冈 山地区生物多样性综合科学考察. 科学出版社, 北京.]

Liu SY, Wu Y (2019) Handbook of the Mammals of China. The Straits Publishing \& Distributing Group, Fuzhou. (in Chinese) [刘少英，吴毅 (2019) 中国兽类图鉴. 海峡书局 出版社, 福州.]

Maine JJ, Boyles JG (2015) Bats initiate vital agroecological interactions in corn. Proceedings of the National Academy of Sciences, USA, 112, 12438-12443.

Moss RH, Edmonds JA, Hibbard KA, Manning MR, Rose SK, Vuuren DP, Carter TR, Emori S, Kainuma M, Kram T, Meehl GA, Mitchell JFB, Nakicenovic N, Riahi K, Smith SJ, Stouffer RJ, Thomson AM, Weyant JP, Wilbanks TJ (2010) The next generation of scenarios for climate change research and assessment. Nature, 463, 747-756.

Olival KJ, Hosseini PR, Zambrana-Torrelio C, Ross N, Bogich TL, Daszak P (2017) Host and viral traits predict zoonotic spillover from mammals. Nature, 546, 646-650.

Posada D, Crandall KA (1998) Modeltest: Testing the model of DNA substitution. Bioinformatics, 14, 817-818.

Rebelo H, Tarroso P, Jones G (2010) Predicted impact of climate change on European bats in relation to their biogeographic patterns. Global Change Biology, 16, 561-576.

Ren RJ, Shi SC, Wu QQ, Deng XJ, Chen YZ (2017) David's myotis (Myotis davidii) found in Hengdong County, Hunan Province, China. Chinese Journal of Zoology, 53, 870-876. (in Chinese with English abstract) [任锐君, 石胜超, 吴倩 倩, 邓学建, 陈意中 (2017) 湖南省衡东县发现大卫鼠耳 蝠. 动物学杂志, 53, 870-876.]

Rusticucci M (2012) Observed and simulated variability of extreme temperature events over South America. Atmospheric Research, 106, 1-17.

Simmons NB (2005) Order Chiroptera. In: Mammal Species of the World: A Taxonomic and Geographic Reference, 3rd edn. (eds Wilson DE, Reeder DM), pp. 312-529. The Johns Hopkins University Press, Baltimore.

Solomon SD, Qin D, Manning M, Chen Z, Marquis M, Avery KB, Tignor M, Miller HL (2007) Climate Change 2007: The Physical Science Basis: Working Group I Contribution to the Fourth Assessment Report of the IPCC. Cambridge University Press, Cambridge.

Stamatakis A (2014) RAxML version 8: A tool for phylogenetic analysis and post-analysis of large phylogenies. Bioinformatics, 30, 1312-1313.

Voigt CC, Kingston T (2016) Bats in the Anthropocene: Conservation of Bats in a Changing World. Springer International Publishing, Cham.

Walsh AL, Morton PA (2009) Methods to promote bats conservation, outreach, and education through science and research-based activities. In: Ecological and Behavioral Methods for the Study of Bats, 2nd edn. (eds Kunz TH, Parsons S), pp. 868-885. The Johns Hopkins University Press, Baltimore.

Wang XY, Zhang QP, Guo WJ, Li F, Chen BC, Xu ZX, Wang YY, Wu Y, Yu WH (2016) Discovery of Murina shuipuensis outside of its type locality-New record from Guangdong and Jiangxi provinces, China. Acta Theriologica Sinica, 36, 118-122. (in Chinese with English abstract) [王 晓云, 张秋萍, 郭伟健, 李锋, 陈柏承, 徐忠鲜, 王英永, 吴毅, 余文华 (2016) 水甫管鼻蝠在模式产地外的发现 一广东和江西省新纪录. 兽类学报, 36, 118-122.]

Wang YX (2003) A Complete Checklist of Mammal Species and Subspecies in China: A Taxonomic and Geographic Reference. China Forestry Publishing House, Beijing. (in Chinese) [王应祥 (2003) 中国哺乳动物物种与亚种分类 名录与分布大全. 中国林业出版社, 北京.]

Wang YY, Chen CQ, Zhao J, Wu Y, Lü ZT, Yang JH, Yu WH, Lin JS, Liu ZY, Wang J, Du Q, Zhang Z, Song YZ, Wang ZR, He GQ (2017) Colored Atlas of Terrestrial Vertebrates of the Jinggangshan Region in China. Science Press, Beijing. (in Chinese) [王英永, 陈春泉, 赵健, 吴毅, 吕植 桐, 杨剑焕, 余文华, 林剑声, 刘祖尧, 王健, 杜卿, 张 忠, 宋玉赞, 汪志如, 何桂强 (2017) 中国井冈山地区陆 生脊椎动物彩色图谱. 科学出版社. 北京.]

Wanger TC, Darras K, Bumrungsri S, Tscharntke T, Klein AM (2014) Bat pest control contributes to food security in Thailand. Biological Conservation, 171, 220-223.

Webb PI, Speakman JR, Racey PA (1995) How hot is a hibernaculum? A review of the temperatures at which bats hibernate. Canadian Journal of Zoology, 74, 761-765.

Wei SG, Li L, Xu R, Huang ZL, Cao HL (2015) Spatial pattern and interspecific relationship of dominant species in plant community in Jinggang Mountain. Journal of Tropical and Subtropical Botany, 23, 74-80. (in Chinese with English abstract) [魏识广, 李林, 许睿, 黄忠良, 曹洪麟 (2015) 井冈山植物群落优势种空间分布格局与种间关联. 热带 亚热带植物学报, 23, 74-80.]

Williamsguillén K, Prefecto I, Vandermeer J (2008) Bats limit insects in a neotropical agroforestry system. Science, 320, 70.

Wong S, Lau S, Woo P, Yuen KY (2010) Bats as a continuing 
source of emerging infections in humans. Reviews in Medical Virology, 17, 67-91.

Xu ZX, Yu WH, Wu Y, Wang YY, Chen CQ, Zhao J, Zhang Z, Li YC (2013) A new record bat of Coelops frithii in Jiangxi Province, China. Sichuan Journal of Zoology, 32, 263-266, 268. (in Chinese with English abstract) [徐忠鲜, 余文华, 吴毅, 王英永, 陈春泉, 赵健, 张忠, 李玉春 (2013) 江 西省翼手目一新纪录—无尾蹄蝠. 四川动物, 32, 263-266, 268.]

Yang QS, Xia L, Feng ZJ, Ma Y, Quan GQ, Wu Y (2007) A guide to the measurement of mammal skuM. Insectivora and Chiroptera. Chinese Journal of Zoology, 42(2), 56-62. (in Chinese with English abstract) [杨奇森, 夏霖, 冯祚建, 马勇, 全国强, 吴毅 (2007) 兽类头骨测量标准 V: 食虫 目、翼手目. 动物学杂志, 42(2), 56-62.]

Yu WH, Hu YF, Guo WJ, Li F, Wang XY, Li YC, Wu Y (2017) New discovery of Harpiocephalus harpia in Hunan Province and its potential distribution area in China. Journal of Guangzhou University (Natural Science Edition), 16(3), 15-20. (in Chinese with English abstract) [余文华, 胡宜峰, 郭伟健, 黎舫, 王晓云, 李玉春, 吴毅 (2017) 毛翼管鼻 蝠在湖南的新发现及中国适生分布区预测. 广州大学学 报(自然科学版), 16(3), 15-20.]

Yu ZH, Wu QQ, Shi SC, Ren RJ, Liu YM, Feng L, Deng XJ (2018) The Kashmir cave myotis (Myotis longipes) was found in Hengdong County, Hunan Province, China. Chinese Journal of Zoology, 53, 701-708. (in Chinese with English abstract) [余子寒, 吴倩倩, 石胜超, 任锐君, 刘宜 敏, 冯磊, 邓学建 (2018) 湖南衡东县发现长指鼠耳蝠. 动物学杂志, 53, 701-708.]

Yue Y, Hu YF, Lei BY, Wu Y, Wu H, Liu BQ, Yu WH (2019)
Sexual dimorphism in Harpiocephalus harpia and its new records from Hubei and Zhejiang, China. Acta Theriologica Sinica, 39, 142-154. (in Chinese with English abstract) [岳 阳, 胡宜峰, 雷博宇, 吴毅, 吴华, 刘宝权, 余文华 (2019) 毛翼管鼻蝠性二型特征及其在湖北和浙江的分布 新纪录. 兽类学报, 39, 142-154.]

Zhang PL, Huang TF, Zhang YX, Liu ZX (2019) The checklist, distribution and conservation of Chiroptera in Wulingshan Region, China. International Journal of Ecology, 8(2), 57-64. (in Chinese with English abstract) [张佩玲, 黄太福, 张佑祥, 刘志霄 (2019) 武陵山区翼手目物种名录、分布 及保护. 世界生态学, 8(2), 57-64.]

Zhang QP, Yu WH, Wu Y, Xu ZX, Li F, Chen BC, Harada M, Motokawa M, Wang YY, Li YC (2014) A new record of Tylonycteris robustula in Jiangxi Province, China and its karyotype. Sichuan Journal of Zoology, 33, 746-749, 757. (in Chinese with English abstract) [张秋萍, 余文华, 吴毅, 徐忠鲜, 李锋, 陈柏承, 原田正史, 本川雅治, 王英永, 李玉春 (2014) 江西省蝙蝠新纪录一一褐扁顽蝠及其核 型报道. 四川动物, 33, 746-749, 757.]

Zhang RZ (1999) Zoogeography of China. Science Press, Beijing. (in Chinese) [张荣祖 (1999) 中国动物地理. 科学 出版社, 北京.]

Zhao WY (2017) The Floristic Phytogeography of Spermatophyte Flora in Luoxiao Range. PhD dissertation, Sun Yat-Sen University, Guangzhou. (in Chinese with English abstract) [赵万义 (2017) 罗霄山脉种子植物区系 地理学研究. 博士学位论文, 中山大学, 广州.]

(责任编委: 蒋学龙 责任编辑: 问文杰)

\section{附录 Supplementary Material}

\section{附录1 罗霄山脉翼手目调查位点}

Appendix 1 The coordinate points of chiropteran investigation in the Luoxiao Mountains http://www.biodiversity-science.net/fileup/PDF/2019259-1.pdf 